\title{
Human amniotic epithelial cells are morphologically homogeneous: enzymehistochemical, tracer, and freeze-substitution fixation study
}

R. Iwasaki, S. Matsubara, T. Takizawa, ${ }^{*}$ T. Takayama, T. Yashiro, ${ }^{*}$ M. Suzuki

Department of Obstetrics and Gynecology, Jichi Medical School; *Department of Anatomy, Jichi Medical

School, Japan

(C)2003, European Journal of Histochemistry

We examined the fine subcellular morphology of human amniotic epithelial cells and attempted to answer the question as to whether amniotic epithelial cells consist of heterogeneous or homogeneous cells, which has long been controversial. Study subjects were fetal membranes from pregnant women $(n=18)$ who abdominally gave birth to healthy infants at term $(37.9 \pm 0.7$ weeks of gestation, mean \pm sd). The methods employed were transmission electron microscopy, enzymehistochemistry, tracer permeability analysis, and freeze-substitution fixation. The labelings for acid phosphatase, cytochrome $\mathrm{c}$ oxidase, and $\mathrm{CA}^{++}$ATPase were seen in the lysosomes, mitochondria, and lateral plasma membranes, respectively. The staining distribution pattern of these three enzymes and the morphology of the organelle highlighted by these enzymehistochemistry did not differ among cells. Freeze-substitution fixation revealed that intercellular spaces in the amniotic epithelial cells were narrower than previously thought, but the tracers (horse radish peroxidase and lanthanum nitrate) fully entered these spaces. There were no variations in the tracer permeability among cells. All cells from freeze-substitution fixation exhibited the same morphological features. From these morphological viewpoints, we conclude that human term amniotic epithelial cells consist of a homogeneous cell population.

Key words: amniotic epithelium, cytochrome c oxidase, enzyme histochemistry, tracer, freeze-substitution fixation

Correspondence: R. Iwasaki, Department of Obstetrics and Gynecology, Jichi Medical School, Minamikawachi-machi 3311-1, Kawachi-gun, Tochigi 329-0498, Japan.

E-mail: iwasakit@jichi.ac.jp

Paper accepted on March 27, 2003

European Journal of Histochemistry

2003; vol. 47 issue 3 [Jul-Sept]: 223-232
The human placenta consists of two parts: placental villi and fetal membranes (the chorioamnion), and the latter are composed of two parts: the chorion and the amnion (Benirschke and Kaufmann, 2000a). While the predominant cells of the chorion are trophoblasts (chorion laeve trophoblasts), similar to the placental villi, and the chorion therefore has a strong resemblance to the villous part of the placenta both in its morphology and its function (Matsubara and Sato 2000; 2001a; Matsubara et al. 2001a;b; c), the amnion lacks trophoblasts. Instead, the amniotic epithelium consists of unique epithelial cells: amniotic epithelial cells. Amniotic epithelial cells exhibit quite characteristic morphological features. They have a relatively small number of intracytoplasmic organelles, microvilli on the apical surface, abundant cytoplasmic processes to the lateral and basal sides, and loose intercellular connections between each other (Benirschke and Kaufmann 2000a).

The fetal membranes are not merely coverings for the amniotic fluid. They protect the fetus from bacterial infection (Benirschke and Kaufmann, 2000b; Matsubara et al. 2000a; Matsubara and Sato 2001a), may modulate the initiation of labor (Okazaki et al. 1981; Sbarra et al. 1983; Sagawa et al. 1994), and produce a number of substances essential to the maintenance of pregnancy (Sagawa et al. 1994; Benirschke and Kaufmann, 2000a). In particular, amniotic epithelial cells have direct contact with the amniotic fluid, and thus they directly contribute to providing the intrauterine milieu for the fetus. Furthermore, human amnion has recently been used as a substrate for organ transplantation, including cornea (Lee and Tseng 1997) and vagina (Bleggi-Torres 1997), and thus this organ/cells has attracted wide attention, not only in reproductive medicine but also transplantation medicine.

Regardless of this, little attention has been paid to their morphology. Approximately 40 years ago, 
Thomas (1965) demonstrated that there were two distinct types of cells in amniotic epithelial cells: they were characterized by distinct/different types of organelle and had different cytoplasmic darkness. She suggested that these epithelial cells consisted of heterogeneous cell populations, solely from the ultrastructural viewpoint. Since then, the heterogeneity of the amniotic epithelial cells has long been argued by several researchers: some agreed (Armstrong et al. 1968; Wynn and French 1968; McCoshen et al. 1981) while others denied this possibility (Lister 1968; Sinha 1971; Hoyes 1972; Sonek et al. 1991). To date, the heterogeneity/homogeneity of the amniotic epithelial cells has not yet been determined. Are human amniotic epithelial cells homogeneous or heterogeneous? This study was an effort to answer this question. We reevaluated the cellular and subcellular structures of human amniotic epithelial cells and characterized their morphological features. We employed ultrastructural enzymehistochemistry, a tracer technique, and a freeze-substitution fixation technique, in addition to conventional transmission electron microscopic observation.

\section{Materials and Methods}

\section{Specimen collection and transmission electron microscopy}

After obtaining informed consent from all the women, amnions were taken from 18 term Japanese

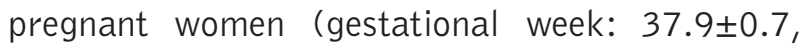
mean \pm sd (range 37.0-39.4), immediately after Cesarean delivery. All women maintained an uncomplicated obstetrical course and gave birth to healthy term infants by Cesarean section before the onset of labor. Cesarean sections were performed due to breech presentation or previous Cesarean sections. Some reports have indicated that there are slight but significant differences in regard to the morphology of fetal membrane cells between the part just beneath the internal ostium vs the other areas (Malak and Bell 1994; McLaren et al. 1999). Therefore, we took 3-4 pieces of reflected amnion from the area $5 \mathrm{~cm}$ from the placental edge and not overlying the internal ostium. Pieces were fixed in $2 \%$ glutaraldehyde solution in Cacodylate buffer $(0.1 \mathrm{M}, \mathrm{pH} 7.4)$ for $120 \mathrm{~min}$ at $4^{\circ}$ for transmission electron microscopy (TEM). For the ultrastructural enzymehistochemistry, tissues were fixed in various concentrations of glutaraldehyde solution. The concentration of glutaraldehyde (0.25$2.0 \%$ ) and the fixation time (5-120min) were determined according to the enzyme as cited previously (references cited in the corresponding part). Specimens were washed in Cacodylate buffer, dehydrated in graded ethanol, postfixed in buffered $1 \%$ Os04, and embedded in epoxy resin Quetol 812. Ultrathin sections were prepared with an LKB Ultrotome III, and observed under a Hitachi $\mathrm{H}$ 7000 transmission electron microscope.

\section{Enzymehistochemistry}

We tried to detect the following ten enzymes. All these enzymes have been proved to play important roles in the placenta, especially in the placental trophoblasts, and we have already enzymehistochemically demonstrated their presence in human placental villous trophoblasts. The fixed specimens were sectioned to $40 \mu \mathrm{m}$ with a freezing microtome, and the detection of enzyme activity was performed as previously reported by our group: acid phosphatase (cerium method, Robinson and Karnovsky 1983; Matsubara et al. 2000b), cytochrome c oxidase (CCO) (DAB method, Seligman et al. 1968; Matsubara et al. 2000b), $\mathrm{Ca}^{++}$ATPase (lead citrate method, Ando et al. 1981; Matsubara et al. 1987a), alkaline phosphatase (cerium method, Robinson and Karnovsky 1983; Matsubara et al. 1987b; 2000b), glucose-6-phosphatase (cerium method, Asaka et al. 1991; Matsubara et al. 1999; 2001a), glucose-6-phosphate dehydrogenase (copper ferrocyanide method, Ishibashi et al. 1999; Matsubara et al. 2001d; Matsubara 2002a;b), ADP-degrading enzymes (lead nitrate method, Matsubara et al. 1997a; 2001c), NADPH oxidase (cerium method, Briggs et al. 1975; Matsubara and Sato 2001a), adenylate cyclase (lead citrate method, Matsubara et al. 1987c), and guanylate cyclase (lead citrate method, Matsubara et al. 1987c). Cytochemical negative controls (ie, substrate omission/inhibitor addition from/to the reaction medium, heating the sections before the cytochemical reaction, etc: described in detail in the corresponding references) were performed to ensure the specific detection of each enzyme activity.

\section{Tracer study}

The fetal side of the membranes was exposed to horse radish peroxidase (type $I V, 3 \mathrm{mg} / \mathrm{mL}$ in 


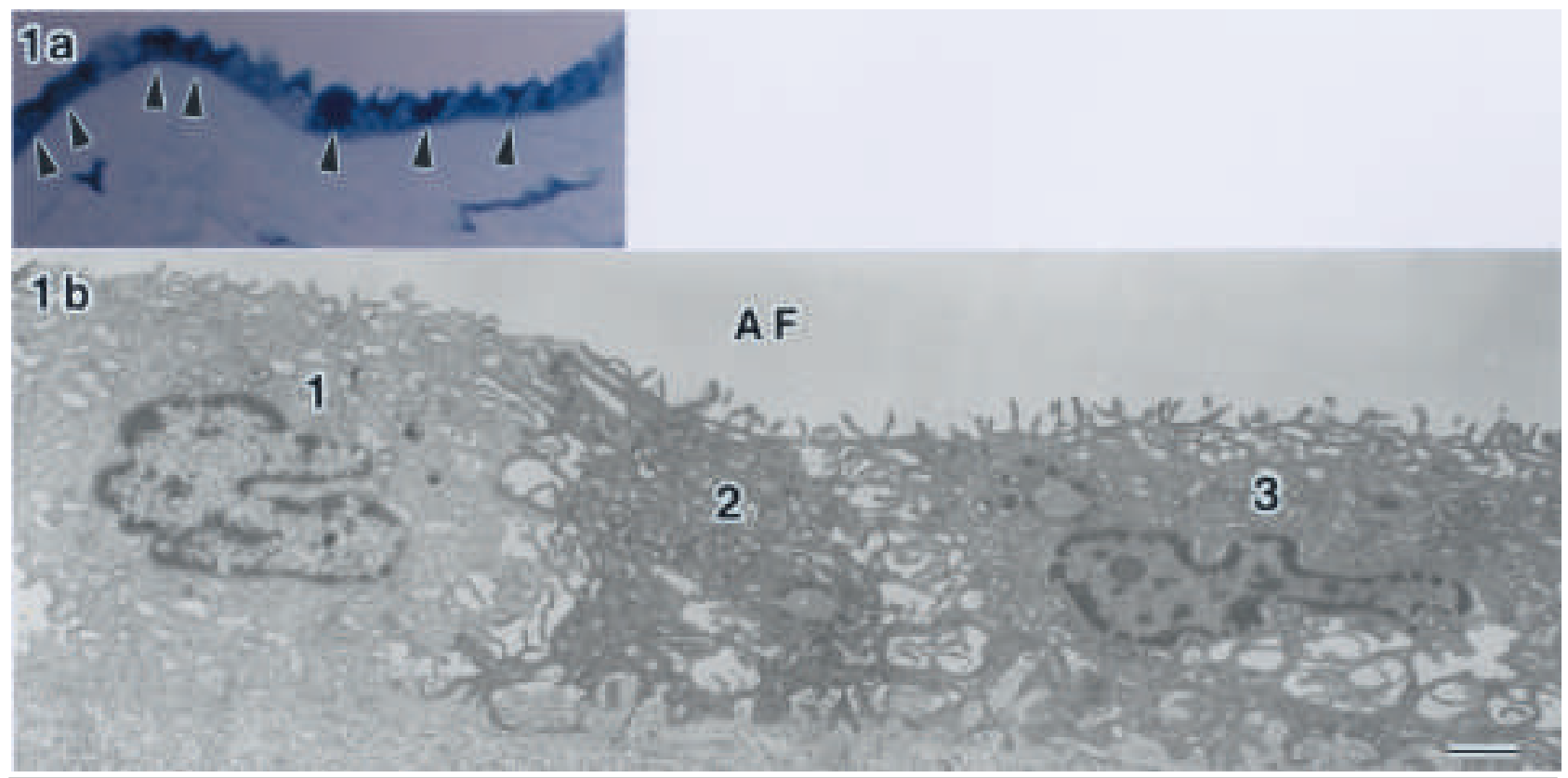

Figure 1. Human term amniotic epithelial cells. Glutaraldehyde fixation. Bar=1 $\mu \mathrm{m}$ (a) Light microscopic observation. A section of 1 $\mu \mathrm{m}$ thickness from an epon-embedded specimen. Toluidine blue staining. Some cells possess darker cytoplasm (arrowheads), while others have lighter cytoplasm. Objective; x40 (b) TEM observation. Three cells are observed (numbered 1 to 3 ). Cell number 1 exhibits lighter cytoplasm compared to the other cells ( 2 and 3$)$. AF: amnitic fluid side.

Hanks solution) or lanthanum nitrate $(3 \%$ in $0.05 \mathrm{M}$ Tris- $\mathrm{HCl}$ buffer, $\mathrm{pH} 7.3$ ) for 1-15 min, the opposite side being bathed in Hanks solution alone. These specimens were fixed in $2 \%$ glutaraldehyde solution in $0.1 \mathrm{M}$ Cacodylate buffer for $30 \mathrm{~min}$ at $4^{\circ}$. For the cytochemical detection of the exogenous horse radish peroxidase, specimens were incubated in diaminobenzidine medium for $10 \mathrm{~min}$ at room temperature (Graham and Karnovsky 1966). Specimens after lanthanum exposure were also processed with the freeze-substitution fixation cited below.

\section{Freeze-substitution fixation}

Small pieces of the fetal membranes $(0.3 \mathrm{~cm}$ in diameter) were rapidly frozen by smashing them against the surface of a liquid nitrogen precooled copper block using the E7200 Slammer quickfreezing device (Polaron; Watford, UK), as previously described (Takizawa et al. 1998). The frozen sections were freeze-substituted in $2 \%$ 0s04-aceton at $-80^{\circ}$ for 3 days. The temperature was then increased to $-20^{\circ}$ for $1 \mathrm{~h}$, to $4^{\circ}$ for $\mathrm{lh}$, and then to room temperature. The specimens were washed three times in absolute acetone and embedded in epoxy resin (Quetol 812).

\section{Results}

Concerning the following morphological features, there were no variations among the specimens from the same amnion (intra-subject variations) or among the subjects studied (inter-subject variations), and thus we will describe the representative findings below.

\section{Conventional TEM study (Figures 1a,b)}

Figure la shows the light microscopic observation of the amniotic epithelial cells. These consisted of a single cell layer and covered the apical, amnioticfluid-side surface of the amnion. There were cells with different cytoplasmic darkness: some cells possessed a dark cytoplasm and others a light cytoplasm. Figure Ib shows the TEM observation. The cells possessed small mitochondria and some endoplasmic reticula. Microvilli were observed in the apical side. Intercellular spaces were wide, and were occupied by abundant cytoplasmic processes, which were connected by desmosomes. These findings fundamentally agreed well with those described by other researchers (Benirschke and Kaufmann 2000a). There were slight variations in regard to the cytoplasmic darkness, but the morphological characteristics cited above appeared the same among cells with different cytoplasmic darkness. 

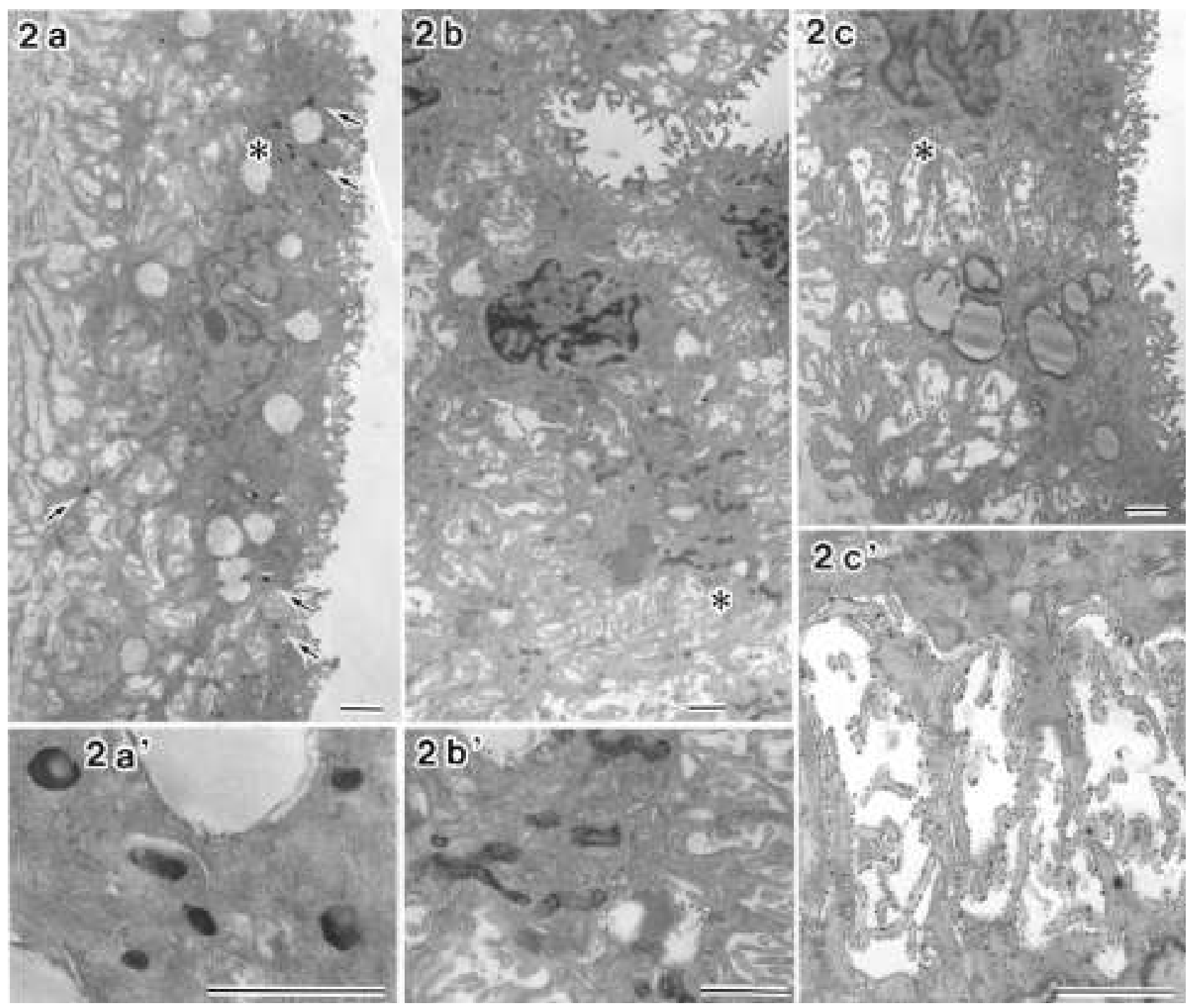

Figure 2. Enzymehistochemistry on human amniotic epithelial cells. Bar=1 $\mu \mathrm{m} 2 \mathrm{2a}$, a'. Acid phosphatase. (a) Electron-dense deposits indicative of acid phosphatase activity are visible in the oval or elongated intracytoplasmic structures (arrows). The area indicated by an asterisk is shown in Figure 2a' at a higher magnification. (a') Acid phosphatase-positive structures. They are considered to be lysosomes. 2b, b'. Cytochrome c oxidase (CCO). (b) CCO labeling on the mitochondria. Amniotic epithelial cell layers were sectioned in the plane parallel to the amnion, and thus several cells are seen side-by-side, not making a single cell layer. All cells possess mitochondria of the same shape, which was highlighted by $\mathrm{CCO}$ enzymehistochemistry. The area indicated by an asterisk is shown in Figure $\mathbf{2 b}^{\prime}$ at a higher magnification. (b') CCO labeling in the mitochondria. 2c, $c^{\prime}$. Ca+'ATPase. (c) Electron-dense deposits indicating $\mathrm{Ca}^{++}$ATPase activity are seen on the lateral plasma membranes. The area marked by an asterisk is shown in Figure $2 \mathrm{c}^{\prime}$. (c') $\mathrm{Ca}^{++} \mathrm{ATPase}$ labeling is visible on the lateral plasma membranes.

\section{Enzymehistochemistry (Figures 2a-c)}

The amniotic epithelial cells exhibited positive stainings for the following three enzymes; acid phosphatase (Figures 2a, $a^{\prime}$ ), cytochrome $c$ oxidase (Figures $\left.2 b, b^{\prime}\right)$, and $\mathrm{Ca}^{++}$ATPase (Figures $2 c, c^{\prime}$ ). The electron-dense deposits indicating acid phosphatase activity were visible in the oval, elongated intracytoplasmic structures throughout the cytoplasm (Figures $2 \mathrm{a}, \mathrm{a}^{\prime}$ ). These structures were considered to be lysosomes. Acid phosphatase-positive lysosomes were evenly distributed among the cells: there were no differences among the cells as far as lysosome distribution was concerned. There were no findings, such as phagosomal formation, fusion of lysosomes to the phagosomes/plasma membranes, or the appearance of the acid phosphatase to the phagosomal membranes, which we have shown to be the histochemical signs of phagocytosis (Matsubara et al. 2000a). CCO labelings were observed in the mitochondria in their intermembrane spaces and intracristal spaces (Figures 2b, b'), which agreed well with our previous observations in other cells 
(Matsubara et al. 1997b; Matsubara et al. 2000b). Mitochondria, highlighted by CCO stainings, were present all throughout the cytoplasm, and there were no CCO-negative mitochondria (Figures $2 \mathrm{~b}$, $\left.b^{\prime}\right)$. No variations were seen regarding the $\mathrm{CCO}$ staining/mitochondria among the cells (Figures $2 b$, $\left.b^{\prime}\right)$. Labelings for $\mathrm{Ca}^{++}$ATPase were seen on the lateral plasma membranes of the cells (Figures $2 c_{,} c^{\prime}$ ), which coincided well with our previous findings in placental villous trophoblasts (Matsubara et al. 1987a). There were no variations/differences concerning the staining pattern/densities for $\mathrm{Ca}^{++}$ATPase among the epithelial cells observed. The cytochemical negative control experiments (ie; substrate omission, inhibitor addition, heating the section) abolished the stainings of the corresponding enzymes (data not shown).

The other seven enzymes studied, ie, alkaline phosphatase, glucose-6-phosphatase, glucose-6-phosphate dehydrogenase, ADP-degrading enzymes, NADPH oxidase, adenylate cyclase, and guanylate cyclase, produced no deposits under these experiment conditions, although our previous studies showed positive labeling for them in the placental villous trophoblasts (Matsubara et al. 1987b; 1999; 2001d; 1997a; Matsubara and Sato 2001b; Matsubara et al. 1987c; 1987c, respectively).

\section{Tracer study (Figures 3a-c)}

At one minute of contact, the tracers (horse radish peroxidase or lanthanum nitrate) entered the intercellular spaces and reached the basement membranes of the amniotic epithelial cells in the chemical fixation specimens (Figures $3 a, b$ ). Freeze-substitution fixation specimens gave the same results for lanthanum permeability (Figure 3c). There were no variations among the cells as far as tracer entering was concerned.

\section{Freeze-substitution fixation (Figures 4a-d)}

Figure $4 a$ shows the light microscopic observation. Cells with the same cytoplasmic darkness lay side-by-side: there were no cells with different cytoplasmic darkness. The ultrastructural morphology of the cells seemed to be fundamentally the same as that in the conventional chemical fixation as cited above. However, the intercellular spaces of the amniotic epithelial cells were very tight (Figures $4 b-d$ ), compared to the observations obtained by chemical fixation. Besides the desmosomal junctions (Figure 4c, d), gap junctions were observed
(Figures $4 d$ ). Although the intercellular spaces were narrow, the tracers entered these spaces, similar to the chemical fixation cited above.

\section{Discussion}

This study confirmed that 1) all the amniotic epithelial cells observed exhibited the same enzymehistochemical staining pattern, 2) the tracers, horseradish peroxidase and lanthanum, entered the intercellular spaces of all the epithelial cells: there were no variations of cells in tracer permeability, and 3) freeze-substitution fixation showed that all the cells possessed cytoplasm with the same darkness, and they had the same ultrastructural features. This indicated that human amniotic epithelial cells exhibited the same morphocytochemical features as far as the enzyme-histochemistry, tracer permeability, and freeze-substitution fixation analysis were concerned. We, therefore, concluded that amniotic epithelial cells consist of homogeneous, and not heterogeneous, cells.

Enzymehistochemistry is a good tool for elucidating the heterogeneity of cell populations. For example, glucose-6-phosphatase enzymehistochemistry revealed distinct cell populations in rat synovial membrane cells (Inaba et al. 1997). These cells (type III synovial cells) showed a characteristic staining pattern for this enzyme, which has never been shown by ordinary TEM morphological analysis without enzymehistochemistry. Using dual staining enzymehistochemistry for acid phosphatase and glucose-6-phosphate dehydrogenase, the heterogeneity of mouse Kupffer cells in terms of phagocytosis function has also been demonstrated by our group (Matsubara 2002a). Furthermore, using CCO enzymehistochemistry and glucose-6-phosphatase enzymehistochemistry, we demonstrated that the morphological features of chorion laeve trophoblasts resembled those of villous syncytiotrophoblasts rather than villous cytotrophoblasts, indicating the close functional/morphological resemblance between chorion laeve trophoblasts and syncytiotrophoblasts (Matsubara et al. 2001b). Enzymehistochemistry also clarified the cell functions in a cell-by-cell manner. For example, we found CCO-negative mitochondria and plasma membranes with reduced staining for ADP-degrading enzymes in preeclamptic villous trophoblasts, although the morphology of the mitochondria and the plasma membranes appeared the same under 


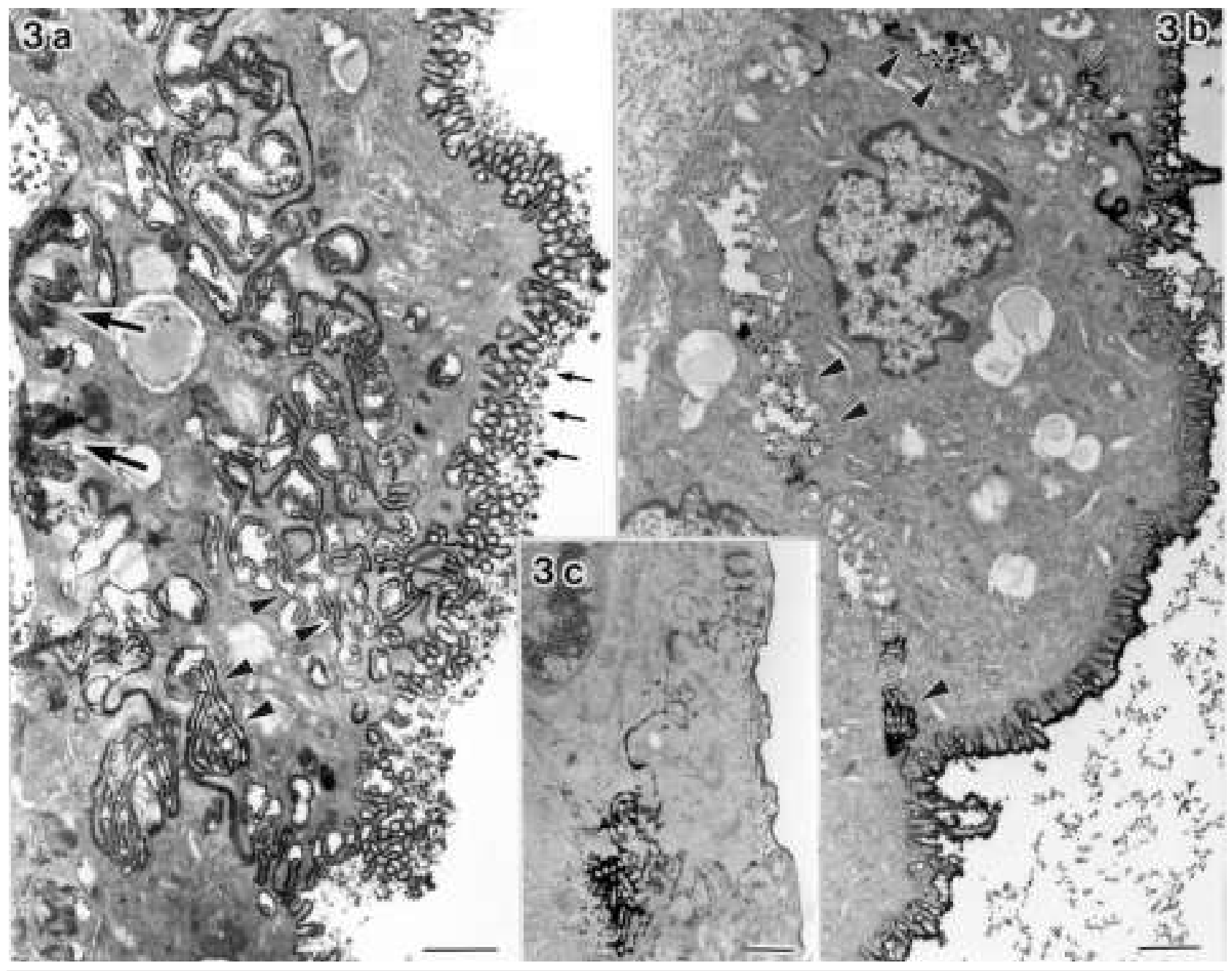

Figure 3. Tracer permeability in the amniotic epithelial cells. Bar=1 um (a) Horse radish peroxidase permeability. Glutaraldehyde fixation. Horse radish peroxidase, with the amniotic fluid side (apical side) being bathed (small arrows), enters the intercellular spaces (arrowheads), and reaches the basement membranes (large arrows). (b) Lanthanum nitrate permeability. Glutaraldehyde fixation. Deposits indicative of lanthanum enter the intercellular spaces (arrowheads). (c) Lanthanum nitrate permeability. Freeze-substitution fixation. Lanthanum enters the intercellular spaces, although the intercellular spaces look tighter than those demonstrated by conventional chemical (glutaraldehyde) fixation.

ordinary TEM observation. We concluded that there were dysfunctions at each cell level in the preeclamptic trophoblasts, and proposed trophoblast responsive hypothesis for the pathogenesis of preeclampsia (Matsubara et al. 1997a; b). In this study, amniotic epithelial cells exhibited stainings for acid phosphatase, $\mathrm{CCO}$, and $\mathrm{Ca}^{++} \mathrm{ATPase}$ in the lysosomes, mitochondria, and lateral plasma membranes, respectively. The staining pattern of these three enzymes and the corresponding organelle highlighted by these enzymehistochemistry (lysosomes, mitochondria, and plasma membranes), showed the same features/architecture. Enzymehistochemistry revealed no differences/het- erogeneity in amniotic epithelial cell morphology.

The amniotic epithelium is in direct contact with the amniotic fluid, and thus it serves as the covering layer of this fluid compartment. In the amniotic epithelium, desmosomes were the predominant type of cell junction. There were no tight junctions, and therefore, this epithelium is considered to be a relatively leaky membrane, as suggested by other researchers (Thomas 1965; King 1982; Bartels and Wang 1983). Since one of the important functions of this epithelium is to cover/seal the amniotic fluid, it is highly probable that there may be some differences in tracer permeability if heterogeneous cell populations do exist in these epithelial cells. 


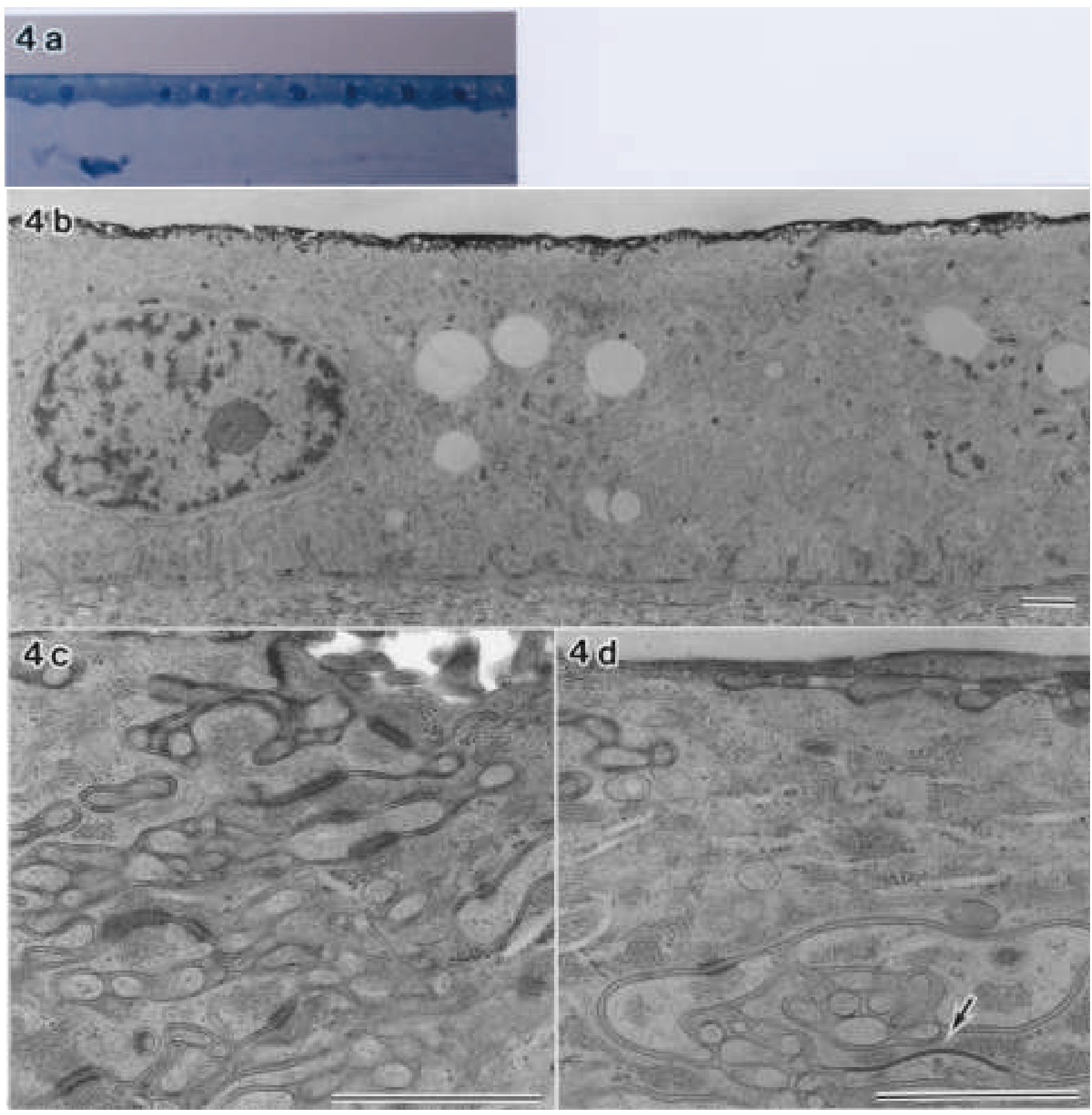

Figure 4. Human term amniotic epithelial cells revealed by freeze-substitution fixation. Bar=1 um (a) Light microscopy. All epithelial cells exhibit the same cytoplasmic density. Objective; x40 (b) TEM observation. Two epithelial cells are seen. The fine subcellular structures are well preserved. (c) Intercellular spaces at a higher magnification. Intercellular spaces are tighter than previously demonstrated by glutaraldehyde fixation. Desmosomes are observed. (d) Another intercellular space. At the junctional structure marked by an arrow, the intercellular cleft is narrowed and is of constant width throughout. This structure is considered to be a gap junction.

This study rejected this possibility. The tracer studies for both the chemical fixation specimens and freeze-subsitution-fixation specimens showed the same results: there were no variations in regard to tracer distribution; horseradish peroxidase and lanthanum nitrate entered the intercellular spaces of all the cells observed. The tracer study also showed no heterogeneous cell populations.

Thomas (1965) demonstrated two types of cells in the human amniotic epithelial cells; light cells and dark cells. The former possessed abundant cytoplasmic organelle (mitochondria, dilated rough endoplasmic reticula, and Golgi apparatus) and lighter cytoplasm, whereas the latter had few 
organelle and darker cytoplasm. She suggested that these two cells represented distinct cell populations and that they performed different functions in the human amniotic epithelium. While some other researchers also supported this view (Armstrong et al. 1968; Wynn and French 1968; McCoshen et al. 1981), others rejected this possibility (Lister 1968; Sinha 1971; Hoyes 1972) or made no mention of the cell types (Sonek et al. 1991; McLaren et al. 1999). All these previous studies, however, employed only conventional chemical (glutaraldehyde) fixation followed by simple TEM observation, and did not use other morphological methodologies. Though not so evident as Thomas indicated, the present glutaraldehyde-fixation specimens also gave slight variations in cells with regard to the cytoplasmic darkness. Histochemists, however, know well that cytoplasmic darkness may be artifactually brought about by the fixation condition. So, it is possible that conventional chemical fixation by glutaraldehyde employed by the earlier researchers may have resulted in variations in the cytoplasmic staining densities. Freeze-substitution fixation preserves cells in a form close to that in the living state, and thus it may give a better morphology than conventional chemical fixation. The present freeze-substitution-fixation specimens showed the fine subcellular morphology of the amniotic epithelial cells, confirming that the intercellular spaces of amniotic epithelial cells are tighter than previously thought, although they may still be leaky to tracers. This fixation finally revealed that there were no variations in either the morphology or the cytoplasmic darkness of the amniotic epithelial cells. There were no two distinct cell populations: light cells and dark cells. In conclusion, we have settled the decadeslong argument about the homogeneity/heterogeneity of amniotic epithelial cells. Solely from the morphological viewpoint, amniotic epithelial cells consist of homogeneous, and not heterogeneous, cells. It was reported that the morphological features of amniotic epithelial cells changed in pathological conditions such as diabetes mellitus-complicated pregnancy (Wang 1980), rhesus incompatibilitycomplicated pregnancy (Wang 1981), and poly/oligo-hydramnic pregnancy (Hebertson et al. 1986). Therefore, our observations may be useful as fundamental data for further clarifying the function of human fetal membranes both in normal and pathological pregnancies.

\section{References}

Ando T, Fujimoto K, Mayahara H, Ogawa K. A new one step method for the histochemistry and cytochemistry of Ca++ATPase activity. Acta Histochem Cytochem 1981;14:705-26.

Armstrong WD, Wilt JC, Pritchard ET. Vacuolation in the human amniotic cell studied by time-lapse photography and electron microscopy. Am J Obstet Gynecol 1968;102:932-48.

Asaka Y, Watanabe J, Kanai K, Kanamura S. High glucose-6-phosphatase activity in non-pigmented epithelial cells of rabbit ciliary body. J Histochem Cytochem 1991;39:1113-20.

Bartels $\mathrm{H}$, Wang T. Intercellular junctions in the human fetal membranes, a freeze-fracture study. Anat Embryol 1983;166:103-20.

Benirschke K, Kaufmann P. Anatomy and pathology of the placental membranes. In the Pathology of the Human Placenta. Benirschke K. and Kaufmann P, editors. Springer-Verlag, New York; 2000a. p. 281-334.

Benirschke K, Kaufmann P. Infectious diseases. In the Pathology of the Human Placenta. Benirschke K. and Kaufmann $\mathrm{P}_{\text {, editors. }}$ Springer-Verlag, New York. 2000b. p. 591-684.

Bleggi-Torres LF, Werner B, Piazza MJ. Ultrastructural study of the neovagina following the utilization of human amniotic membrane for treatment of congenital abscence of vagina. Braz J Med Biol Res 1997;30:861-4.

Briggs RT, Drath DB, Karnovsky ML, Karnovsky MJ. Localization of $\mathrm{NADH}$ oxidase on the surface of the human polymorphonuclear leukocytes by a new cytochemical method. J Cell Biol 1975;67:56686.

Graham RC, Karnovsky MJ. The early stage of absorption of injected horse radish peroxidase in the proximal tubule of the mouse kidney. $J$ Histochem Cytochem 1966;14:291-302.

Hebertson RM, Hammond ME, Bryson MJ. Amniotic epithelial ultrastructure in normal, polyhyramnic, and oligohydramnic pregnancies. Obstet Gynecol 1986;68:74-9.

Hoyes AD. Fine structure of human amniotic epithelium following short-term preservation in vitro. J Anat 1972;111:43-54.

Inaba T, Kariya Y, Hoshino Y, 0oi Y, Yashiro T, Saito T. Glucose-6-phosphatase histochemistry of osteoarthritis. Acta Histochem Cytochem 1997;30:93-103.

King BF. Cell surface specialization and intercellular junctions in human amniotic epithelium: an electron microscopic and freezefracture study. Anat Rec 1982;203:73-82.

Lee SH, Tseng SC. Amniotic membrane transplantation for persistent epithelial defect with ulceration. Am J Ophthalmol 1997;123:30312.

Lister UM. Ultrastructure of the human amnion, chorion and fetal skin. J Obstet Gynaec Br Cwth 1968;75:327-41.

McLaren J, Taylor DJ, Bell SC. Increased incidence of apoptosis in non-labour-affected cytotrophoblast cells in term fetal membranes overlying the cervix. Hum Reprod 1999;14:2895-900.

McCoshen JA, Chudasama S, Tyson JE. Differential responsiveness of cells of human amniotic epithelium to ferritin and 125I-prolactin in vitro. Placenta 1981;3:33-47.

Malak TM, Bell SC. Structural characteristics of term human fetal membranes: a novel zone of extreme morphological alteration within the rupture site. Br J Obstet Gynaecol 1994;101:375-86.

Matsubara S. Glucose-6-phosphate dehydrogenase and mouse Kupffer cell activation: an ultrastructural dual staining enzyme-cytochemical study. Histochem Cell Biol 2002a;118:345-50.

Matsubara S. Simultaneous demonstration of acid phosphatase and glucose-6-phosphate dehydrogenase in mouse hepatocytes. A novel electron-microscopic dual staining enzyme-cytochemistry. Eur J Histochem 2002b;46:237-42.

Matsubara S, Sato I. Enzyme-histochemically detectable glucose-6phosphatase is present in chorion laeve trophoblasts of human fetal membranes. Histochem Cell Biol 2000;113:363-8.

Matsubara S, Sato I. NAD(P)H oxidase in human fetal membrane chorion laeve trophoblasts with or without chorioamnionitis: ultrastructural enzyme histochemical study. Mol Hum Reprod 2001a; 7:779-85.

Matsubara S, Sato I. Enzyme-histochemically detectable NAD(P)H oxidase in human placental trophoblasts -normal, preeclamptic, and 
fetal-growth-restriction complicated pregnancy. Histochem Cell Biol 2001b:116:1-7.

Matsubara S, Tamada T, Saito T. Ultrastructural localizations of adenosine nucleotidase activities in the human term placenta, with special reference to 5'-nucleotidase activity. Acta Histochem Cytochem 1987a;20:409-19.

Matsubara S, Tamada T, Saito T. Ultrastructural localization of alkaline phosphatase and acid phosphatase activities in the human term placenta. Acta Histochem Cytochem 1987b;20:283-94.

Matsubara S, Tamada T, Saito T. Ultracytochemical localization of adenylate cyclase, guanylate cyclase and cyclic $3^{\prime}, 5^{\prime}$-nucleotide phosphodiesterase activity on the trophoblast in the human term placenta. Histochem 1987c;87:505-9.

Matsubara S, Sato I, Saito T. Ultrastructural localization and cytochemical characteristics of human placental ADP-degrading activity in normal and preeclamptic pregnancy. Trophoblast Research 1997a;9:121-9.

Matsubara S, Minakami H, Sato I, Saito T. Decrease in cytochrome c oxidase activity detected cytochemically in the placental trophoblast of patients with preeclampsia. Placenta 1997b;18:255-9.

Matsubara S, Takizawa T, Sato I. Glucose-6-phosphatase is present in normal and preeclamptic placental trophoblast: Ultrastructural enzyme-histochemical evidence. Placenta 1999;20:81-5.

Matsubara S, Takizawa T, Yamada T, Minakami H, Sato I. Phagocytosis of chorion laeve trophoblasts in patients with chorioamnionitis-associated preterm delivery: ultrastructural and enzyme-histochemical observations. Placenta 2000a;21:273-9.

Matsubara S, Takizawa T, Sato I. Enzymehistochemistry on human placental trophoblasts: the effect of fixation delay on enzyme activity. Histochem Cell Biol 2000b;113:287-92.

Matsubara S, Takizawa T, Takayama T, Iwasaki R, Minakami H, Sato I. Cytochemically detectable glucose-6-phosphate dehydrogenase is present in human fetal membrane chorion laeve trophoblasts. Placenta 2001a;22:613-6.

Matsubara S, Takayama T, Iwasaki R, Minakami H, Takizawa T, Sato I. Morphology of the mitochondria and endoplasmic reticula of chorion laeve cytotrophoblasts: their resemblance to villous syncytiotrophoblasts rather than villous cytotrophoblasts. Histochem Cell Biol 2001b;116:9-15.

Matsubara S, Takayama T, Iwasaki R, Izumi A, Watanabe T, Sato I. Chorion laeve trophoblasts of preeclamptic fetal membranes: histo- chemically detectable enzyme activities do not change at a subcellular level. Eur J Histochem 2001c;45:211-7.

Matsubara S, Takizawa T, Suzuki T, Minakami H, Sato I. Glucose-6phosphate dehydrogenase is present in normal and preeclamptic placental trophoblasts. Placenta 2001d;22:90-5.

Okazaki T, Casey ML, Okita JR, MacDonald PC, Johnston JM. Initiation of human parturition. XII. Biosynthesis and metabolism of prostaglandins in human fetal membranes and uterine decidua. Am J Obstet Gynecol 1981;139:373-81.

Robinson JM, Karnovsky MJ. Ultrastructural localization of some phosphatase with cerium. J Histochem Cytochem 1983;31:1197208.

Sbarra AJ, Selvaraj RJ, Cetrulo CL, Thomas G, Louis F, Kennison R. Phagocytosis and onset of human labor. Am J Obstet Gynecol 1983;146:622-9.

Sagawa N, Hasegawa M, Itoh H, Manno H, Mori T, Yano J, et al. The role of amniotic endothelin in human pregnancy. Placenta 1994;15:565-75.

Seligman AM, Karnovsky MJ, Wasserkrug HL, Hanker JS. Nondroplet ultrastructural demonstration of cytochrome oxidase activity with a polymerizing osmiophilic reagent, diaminobenzidine (DAB). J Cell Biol 1968;38:1-14.

Sinha AA. Ultrastructure of human amnion and amniotic plaques of normal pregnancy. Z Zellforsch 1971;122:1-14.

Sonek J, Gabbe SG, Iams JD, Kniss DA. Morphologic changes in the human amnion epithelium that accompany labor as seen with scanning and transmission electron microscopy. Am J Obstet Gynecol 1991;164:1174-80.

Takizawa T, Takizawa T, Arai S, Osumi M, Saito T. Ultrastructure of human scalp hair shafts as revealed by freeze-substitution fixation. Anat Rec 1998;251:406-13.

Thomas CE. The ultrastructure of human amniotic epithelium. J Ultrastruct Res 1965;13:65-84.

Wang T. Amniotic epithelium in diabetes mellitus. Light and electron microscopic examination. Virchows Arch A Pathol Anat Histol 1980;387:185-91.

Wang T. Amniotic epithelium in rhesus incompatibility: light and electron microscopic examination. Placenta 1981;2:35-43.

Wynn RM, French GL. Comparative ultrastructure of the mammalian amnion. Obstet Gynecol 1968;31:759-74. 